\title{
Genótipos de bananeira em três ciclos na Zona da Mata Mineira
}

\author{
Camilo Augusto Pinto de Oliveira(1), Clóvis Pereira Peixoto(1), Sebastião de Oliveira e Silva(2), \\ Carlos Alberto da Silva Ledo(2) e Luiz Carlos Chamhum Salomão(3)
}

\begin{abstract}
(1)Universidade Federal do Recôncavo da Bahia, Centro de Ciências Agrárias, Ambientais e Biológicas, CEP 44380-000 Cruz das Almas, BA. E-mail: camiloaugus@yahoo.com.br, cppeixot@ufba.br (2)Embrapa Mandioca e Fruticultura Tropical, Caixa Postal 7, CEP 44380-000 Cruz das Almas, BA. E-mail: ssilva@cnpmf.embrapa.br, ledo@cnpmf.embrapa.br (3)Universidade Federal de Viçosa, Dep. de Fitotecnia, Av. P.H. Rolfs, s/no, CEP 36570-000 Viçosa, MG. E-mail: Isalomao@ufv.br
\end{abstract}

\begin{abstract}
Resumo - O objetivo deste trabalho foi avaliar, durante três ciclos, as principais características vegetativas dos genótipos Prata Anã, Grande Naine, Caipira, Nam, Pioneira, FHIA-01, FHIA-18, PV03-44 e SH3640, com a finalidade de incorporar novos genótipos aos sistemas de produção comercial. Conduziu-se um experimento na Zona da Mata Mineira durante três ciclos da cultura, em um delineamento experimental de blocos casualizados com nove tratamentos (genótipos) e três repetições (ciclos). Avaliaram-se porte, precocidade, número de folhas, resistência à sigatoka-amarela (Mycosphaerela musicola) e perfilhamento da planta. A variedade Grande Naine apresentou o menor porte, enquanto Prata Anã, FHIA-01 e SH3640, o maior diâmetro. Os genótipos que apresentaram maior precocidade foram Pioneira e FHIA-18. 'Nam' e 'Caipira' apresentaram os maiores números e maior precocidade de perfilhos. Foram identificados como superiores os genótipos FHIA-01, FHIA-18 e SH3640.
\end{abstract}

Termos para indexação: Musa spp., precocidade, híbrido, variedade.

\section{Banana genotypes in three cycles at Zona da Mata Mineira region}

\begin{abstract}
The objective of this work was to evaluate during three cycles the main vegetative characteristics of the genotypes Prata Anã, Grande Naine, Caipira, Nam, Pioneira, FHIA-01, FHIA-18, PV03-44 and SH3640, aiming to incorporate new genotypes to commercial production systems. An experiment was carried out at Zona da Mata Mineira region during three crop cycles, in randomized block design, with nine treatments (genotypes) and three replications (cycles). Height, precocity, number of leaves, resistance to Yellow Sigatoka and plant suckers were evaluated. The variety Grande Naine had the lower height, while Prata Anã, FHIA-01 and SH3640, the larger diameter. The genotypes that presented higher precocity were Pioneira and FHIA-18. The varieties Nam and Caipira presented the highest numbers and precocity of suckers. The genotypes FHIA-01, FHIA-18 and SH3640 were superiors in relation to the characteristics evaluated.
\end{abstract}

Index terms: Musa spp., precocity, hybrid, variety.

\section{Introdução}

A bananeira (Musa spp.) é uma planta de grande importância econômica e social tanto no Brasil como no mundo, com o mais alto índice de consumo per capita entre as frutas tropicais, um comércio tradicional consolidado e bem distribuído (Brasil, 2006). Dados colhidos durante 40 anos de observação pela FAO (2006) revelam que o consumo per capita mundial de banana cresceu $72 \%$ nesse período.

A despeito de o crescimento da produção mundial de banana ter sido significativo, a produção brasileira apresentou aumento abaixo da média mundial, ao longo dos últimos 40 anos (FAO, 2006). Segundo Alves (1997), a falta de variedades comerciais produtivas, com porte adequado e resistentes às principais moléstias de cultivo, assim como o manejo inadequado do sistema soloágua-planta, são os principais fatores que contribuem para a baixa produtividade de banana do Brasil, que gira em torno de 13,5 $\mathrm{tha}^{-1}$, de acordo com dados do IBGE (2006) e FAO (2006).

Entre as doenças que afetam a bananeira, a que tem despertado maior interesse é a sigatoka-negra, considerada a mais prejudicial mundialmente. Causada pelo fungo Mycosphaerella fijiensis Morelet var. difformis, é uma doença devastadora que ataca as folhas destruindo-as completamente, causando perdas de até $100 \%$ nas plantações (Cordeiro \& Matos, 2000). Uma possível solução para esse problema é a busca de novas variedades resistentes. Resultados do programa de me- 
lhoramento da Embrapa Mandioca e Fruticultura Tropical, obtidos por Silva et al. (2001), indicaram que o uso de variedades resistentes é um dos caminhos mais atrativos para o controle de doenças, uma vez que não depende da ação do produtor durante a fase de crescimento das plantas, não é prejudicial ao meio ambiente e, geralmente, é compatível com outras técnicas de manejo.

Estudos comprovam que o desempenho vegetativo de um genótipo reflete sua capacidade produtiva. Leonel et al. (2004) encontraram correlações positivas entre características vegetativas e produtivas, com destaque para número de folhas, altura da planta e diâmetro do pseudocaule. Gaiva (1992) observou que o maior número de folhas na colheita correspondeu a cachos mais pesados em alguns genótipos.

Ainda que exista grande número de variedades de banana no Brasil, quando se consideram características como preferência dos consumidores, produtividade alta, tolerância a pragas e doenças, precocidade, resistência à seca e ao frio, bem como adequação do porte, restam poucas variedades com potencial agronômico para serem usadas comercialmente (Silva et al., 1996).

O objetivo deste trabalho foi avaliar durante três ciclos as principais características vegetativas de nove genótipos de bananeira, com a finalidade de incorporar novos genótipos aos sistemas de produção comercial.

\section{Material e Métodos}

O trabalho foi conduzido durante três ciclos da cultura na Universidade Federal de Viçosa, no período de 1997 a 2001, em um campo experimental localizado em Visconde do Rio Branco, Minas Gerais. A área experimental localiza-se na mesorregião da Zona da Mata Mineira, a uma altitude de 349 m (IBGE, 2006). Dados históricos, coletados na Estação Meteorológica da UFV, registram temperatura média anual de $21,7^{\circ} \mathrm{C}$, com 16,3 e $29,1^{\circ} \mathrm{C}$ de mínima e máxima, respectivamente, umidade relativa média do ar de $79,5 \%$ e precipitação média anual de $1.272 \mathrm{~mm}$.

De acordo com a classificação de Köppen, a área experimental posiciona-se em região de clima do tipo Cwa, caracterizado como clima mesotérmico (subtropical e temperado) com chuvas de verão, apresentando, como característica principal, verões quentes (Ambiente Brasil, 2006; Classificação..., 2006). O solo foi classificado como Argissolo Vermelho-Amarelo câmbico, fase terraço e de topografia plana (Embrapa, 1999).
Antes do plantio, o terreno foi arado, gradeado e a correção do solo foi feita por meio da aplicação de $2 \mathrm{t} \mathrm{ha}^{-1} \mathrm{de}$ calcário dolomítico, seguindo as recomendações da Comissão... (1989). A adubação na cova foi realizada aplicando-se $400 \mathrm{~g}$ de superfosfato simples e $15 \mathrm{~L}$ de esterco de gado curtido. No plantio, utilizou-se o espaçamento de $3 \times 2 \mathrm{~m}$, por ser um dos mais difundidos nos sistemas de produção de bananas cultivadas em sequeiro, e por apresentar a melhor resposta produtiva, de acordo com Pereira et al. (2000) e Zonetti et al. (2003). A primeira adubação de cobertura foi feita aplicando-se $200 \mathrm{~g}$ de sulfato de amônio, $200 \mathrm{~g}$ de cloreto de potássio, $20 \mathrm{~g}$ de bórax e $30 \mathrm{~g}$ de sulfato de zinco por planta, três meses após o plantio. As adubações de cobertura subseqüentes foram realizadas em intervalos de três meses, aplicandose as mesmas doses de sulfato de amônio e de cloreto de potássio. As aplicações de fósforo, zinco e boro foram repetidas anualmente.

Após a primeira adubação de cobertura, foi realizada uma subsolagem nas entrelinhas a $50 \mathrm{~cm}$ de profundidade, com o intuito de auxiliar a penetração do sistema radicular das plantas. A operação foi realizada utilizando-se um subsolador de duas hastes, distando $1 \mathrm{~m}$ uma da outra e $0,50 \mathrm{~m}$ da linha de plantio. A condução do pomar foi feita por meio do desbaste, utilizando-se o sistema de família, que consiste em manter a planta-mãe com uma plantafilha e uma planta-neta, eliminando-se as demais.

O delineamento experimental foi em blocos ao acaso com nove tratamentos e três repetições em parcelas subdivididas no tempo (Banzatto \& Kronka, 1989), sendo os genótipos considerados parcelas, e os ciclos considerados subparcelas. Cada unidade experimental foi composta por 16 plantas úteis.

Os tratamentos foram compostos por nove genótipos, constituídos pelas variedades Prata Anã, Grande Naine, Caipira e Nam, e pelos híbridos Pioneira, FHIA-01, FHIA-18, PV03-44 e SH3640 (Silva et al., 2001; Donato, 2003; Leite et al., 2003; Lima et al., 2005), avaliados durante três ciclos da cultura. Os dados foram submetidos à análise de variância e as médias dos tratamentos que compuseram as parcelas e as subparcelas foram comparadas e agrupadas por meio do teste de agrupamento de Scott-Knott, com auxílio do software SISVAR (Ferreira, 2000).

Em cada ciclo vegetativo, e em cada planta da parcela útil, foram realizadas as seguintes avaliações: altura da planta, diâmetro do pseudocaule, dias do plantio à colheita, dias do plantio ao florescimento, dias do florescimento à colheita, número de folhas vivas no 
florescimento, número de folhas vivas na colheita, incidência de sigatoka-amarela no florescimento, incidência de sigatoka-amarela na colheita e quantidade e época de emissão dos perfilhos.

A altura da planta foi avaliada durante a emissão da inflorescência com o auxílio de uma trena semiflexível posicionada desde o nível do solo até a roseta foliar (ponto de inserção do engaço no pseudocaule), e a medida foi expressa em centímetros.

Na determinação do diâmetro do pseudocaule, foi utilizada uma fita métrica a $0,30 \mathrm{~m}$ acima do nível do solo para medir seu perímetro e posteriormente foi feita a transformação desta medida para diâmetro, por meio da fórmula: $\mathrm{D}=\mathrm{P} / \pi$, em que $\mathrm{D}$ é o diâmetro do pseudocaule; P é o perímetro do pseudocaule.

As características dias do plantio à colheita, dias do plantio ao florescimento e dias do florescimento à colheita foram obtidos por meio do cálculo da diferença entre a data da colheita e a data do plantio, data da emissão da inflorescência e a data do plantio, e data da colheita à data da emissão da inflorescência, respectivamente. $\mathrm{O}$ resultado foi dado em número de dias.

$\mathrm{Na}$ contagem das folhas durante o florescimento e colheita, foram consideradas as totalmente abertas e que apresentaram área verde acima de $10 \%$. O resultado foi dado em número de folhas vivas.

A avaliação da incidência da sigatoka-amarela, durante o florescimento e colheita, foi realizada na quinta folha, contada a partir da mais jovem completamente desenvolvida. Foram atribuídas notas de 0 a 6 , de acordo com a expressão dos sintomas, assim descritos: 0 , nenhum sintoma; 1 , menos de $1 \%$ da lâmina foliar com sintomas; 2,1 a $5 \% ; 3,6$ a 15\%; 4, 16 a 33\%; 5, 34 a $50 \%$; e 6,51 a $100 \%$.
As características quantidade e época de emissão dos perfilhos foram avaliadas sem levar em consideração os ciclos, já que tanto a planta mãe quanto a filha e a neta podem emitir seus perfilhos ao mesmo tempo, dificultando, ou até mesmo impossibilitando, a associação com as respectivas plantas que os geraram. Por este motivo, a avaliação dessas características foi realizada anotando-se a data, e a quantidade de perfilhos emitidos até aquela data.

\section{Resultados e Discussão}

A análise estatística dos dados revelou diferença significativa pelo teste de Scott-Knott, a 5\% de probabilidade, para a maioria das características analisadas.

No primeiro ciclo, os genótipos Grande Naine, Pioneira, Caipira, Prata Anã e FHIA-18 fizeram parte do grupo de menor porte, diferindo do grupo formado pelos genótipos FHIA-01, Nam e SH3640, de porte intermediário, que por sua vez diferiram significativamente de PV03-44, pelo teste de Scott-Knott, a 5\% de probabilidade (Tabela 1). O mesmo resultado foi alcançado por Flores (2000) ao comparar os mesmos genótipos deste trabalho. 'Grande Naine' manteve a posição de genótipo mais baixo nos dois ciclos seguintes, diferindo significativamente dos demais. Por sua vez, o híbrido PV03-44 confirmou sua característica de porte alto (por ter como genitora uma variedade de porte alto, a Pacovan), mantendo isoladamente o posto de genótipo mais alto em todos os ciclos e entre todos os genótipos avaliados.

Na análise da média de cada genótipo nos três ciclos, observa-se a formação de três grupos: o de menor

Tabela 1. Características de desenvolvimento vegetativo na época do florescimento de nove genótipos de bananeira em três ciclos na Zona da Mata Mineira(1).

\begin{tabular}{|c|c|c|c|c|c|c|c|c|}
\hline \multirow[t]{2}{*}{ Genótipo } & \multicolumn{4}{|c|}{ Altura da planta $(\mathrm{cm})$} & \multicolumn{4}{|c|}{ Diâmetro do pseudocaule $(\mathrm{cm})$} \\
\hline & $1^{\circ}$ ciclo & $2^{-}$ciclo & $3^{\circ}$ ciclo & Média & $1^{\circ}$ ciclo & $2^{\circ}$ ciclo & $3^{\circ}$ ciclo & Média \\
\hline Grande Naine & $204,9 a$ & $235,7 \mathrm{a}$ & $258,7 \mathrm{a}$ & $233,1 \mathrm{a}$ & $20,4 \mathrm{a}$ & $24,6 b$ & $26,3 c$ & $23,8 b$ \\
\hline Pioneira & $218,7 \mathrm{a}$ & $289,5 b$ & $350,1 b$ & $286,1 b$ & $18,3 b$ & $23,9 b$ & $30,8 b$ & $24,3 b$ \\
\hline Caipira & $238,7 \mathrm{a}$ & $302,8 b$ & $343,1 b$ & $294,8 b$ & $17,4 \mathrm{~b}$ & $21,1 \mathrm{c}$ & $24,0 \mathrm{c}$ & $20,8 \mathrm{c}$ \\
\hline Prata Anã & $239,3 \mathrm{a}$ & $307,3 b$ & $329,7 b$ & $292,1 b$ & $21,0 \mathrm{a}$ & $27,5 \mathrm{a}$ & $31,9 \mathrm{a}$ & $26,8 \mathrm{a}$ \\
\hline FHIA-18 & $240,5 \mathrm{a}$ & $301,0 \mathrm{~b}$ & $334,6 b$ & $292,0 \mathrm{~b}$ & $20,0 \mathrm{a}$ & $24,4 b$ & $29,6 \mathrm{~b}$ & $24,7 \mathrm{~b}$ \\
\hline FHIA-01 & $251,4 b$ & $316,3 b$ & $362,4 b$ & $310,0 \mathrm{~b}$ & $22,2 \mathrm{a}$ & $27,8 \mathrm{a}$ & $32,7 \mathrm{a}$ & $27,6 \mathrm{a}$ \\
\hline Nam & $257,0 \mathrm{~b}$ & $317,3 b$ & $354,2 \mathrm{~b}$ & $309,5 b$ & $18,8 \mathrm{~b}$ & $22,9 \mathrm{c}$ & $26,1 \mathrm{c}$ & $22,6 \mathrm{c}$ \\
\hline SH3640 & $262,1 \mathrm{~b}$ & $342,2 \mathrm{c}$ & $373,2 b$ & $325,8 b$ & $22,6 a$ & $29,9 a$ & $34,2 \mathrm{a}$ & $28,9 a$ \\
\hline PV03-44 & $293,3 c$ & $396,3 d$ & $442,4 \mathrm{c}$ & $377,3 \mathrm{c}$ & $18,1 \mathrm{~b}$ & $24,3 \mathrm{~b}$ & $28,8 \mathrm{~b}$ & $23,7 b$ \\
\hline Média & $245,1 \mathrm{~A}$ & $312,0 \mathrm{~B}$ & $349,8 \mathrm{C}$ & 302,3 & $19,9 \mathrm{C}$ & $25,1 \mathrm{~B}$ & $29,4 \mathrm{C}$ & 24,8 \\
\hline
\end{tabular}

${ }^{(1)}$ Médias seguidas pela mesma letra, minúscula nas colunas e maiúscula nas linhas, pertencem ao mesmo grupo, pelo teste de Scott-Knott, a 5\% de probabilidade. 
porte, composto apenas pelo genótipo Grande Naine, o de porte intermediário, composto pelos genótipos Pioneira, Caipira, Prata Anã, FHIA-18, FHIA-01, Nam e SH3640, e o grupo de porte alto, representado apenas por PV03-44.

Além do menor porte, 'Grande Naine' também apresentou o menor porcentual de incremento na altura, mostrando tendência de manutenção dessa característica ao longo dos ciclos (Tabela 2). Resultado semelhante foi obtido por Silva et al. (2002). Por sua vez, a maior porcentagem de aumento na altura de planta ocorreu com Pioneira, superando PV03-44 do primeiro para o terceiro ciclo.

Como já era esperado (Ledo et al., 1997; Flores, 2000; Silva et al., 2000, 2002), do primeiro para o segundo ciclo houve aumento na altura das plantas em todos os nove genótipos avaliados.

Os genótipos Prata Anã, FHIA-01 e SH3640 mostraram superioridade no diâmetro do pseudocaule nos três ciclos (Tabela 1), assim como na média desta característica, podendo ser considerados como os genótipos mais vigorosos entre os avaliados. Resultados semelhantes foram obtidos por Pereira et al. (2003), em estudo com os mesmos genótipos. Por outro lado, 'Caipira' e 'Nam' apresentaram os menores diâmetros.

Assim como ocorreu com altura de planta, o diâmetro do pseudocaule foi passível de maior porcentual de incremento (Tabela 2) do primeiro para o segundo ciclo, mantendo a peculiaridade de todos os genótipos promoverem o engrossamento de seus pseudocaules ao longo dos referidos ciclos, como foi também constatado por Flores (2000), Silva et al. (2000) e Leite et al. (2003).

A 'Grande Naine' apresentou o menor aumento de diâmetro em todo o período de avaliação. O maior incremento do primeiro para o segundo ciclo foi conseguido pelo híbrido PV03-44, e do segundo para o terceiro, pelo híbrido Pioneira. Na análise dos três ciclos, o genótipo com maior percentual de incremento foi a variedade Pioneira.

Os genótipos Pioneira e FHIA-18 mostraram ser os mais precoces, na analise dos três ciclos completos (Tabela 3). Por sua vez, 'Caipira' apresentou o primeiro ciclo mais longo. Pereira et al. (2003) também elegeram 'Pioneira' e 'Caipira' como o mais precoce e o mais tardio, respectivamente. É notória a precocidade do híbrido Pioneira, fato constatado em diversos estudos (Silva et al., 2000, 2003b; Donato et al., 2003; Leite et al., 2003; Pereira et al., 2003).

A característica dias do plantio ao florescimento aponta Pioneira como o genótipo mais precoce e Caipira como o mais tardio, na avaliação dos três ciclos.

$\mathrm{Na}$ análise das médias de todos os genótipos em cada ciclo, pôde-se constatar, ainda, que o segundo ciclo se mostrou estatisticamente mais precoce em 14,2 e 7,5 dias, quando comparado ao primeiro e ao terceiro ciclo, respectivamente.

Apesar de os genótipos não apresentarem diferença significativa entre si, a média do número de folhas vivas presentes na planta durante a emissão da inflorescência foi estatisticamente superior no primeiro ciclo (Tabela 4).

Tabela 2. Incremento na altura da planta e no diâmetro do pseudocaule entre os três ciclos dos nove genótipos de bananeira avaliados na Zona da Mata Mineira ${ }^{(1)}$.

\begin{tabular}{|c|c|c|c|c|c|c|}
\hline \multirow[t]{2}{*}{ Genótipo } & \multicolumn{3}{|c|}{ Altura da planta (\%) } & \multicolumn{3}{|c|}{ Diâmetro do pseudocaule (\%) } \\
\hline & $1^{\mathrm{o}} \rightarrow 2^{\mathrm{o}}$ & $2^{\underline{0} \rightarrow 3^{0}}$ & $1^{\mathrm{o}} \rightarrow 3^{\mathrm{o}}$ & $1^{\underline{o}} \rightarrow 2^{\underline{o}}$ & $2^{\mathrm{o}} \rightarrow 3^{\mathrm{o}}$ & $1^{\mathrm{o}} \rightarrow 3^{\mathrm{o}}$ \\
\hline Grande Naine & 15,0 & 9,8 & 26,3 & 20,4 & 7,2 & 29,1 \\
\hline Pioneira & 32,4 & 20,9 & 60,1 & 30,1 & 29,0 & 67,8 \\
\hline Caipira & 26,8 & 13,3 & 43,7 & 21,6 & 13,5 & 38,1 \\
\hline Prata Anã & 28,4 & 7,3 & 37,8 & 30,8 & 16,1 & 51,9 \\
\hline FHIA-18 & 25,1 & 11,2 & 39,1 & 21,7 & 21,3 & 47,7 \\
\hline FHIA-01 & 25,8 & 14,6 & 44,2 & 25,2 & 17,5 & 47,1 \\
\hline Nam & 23,4 & 11,7 & 37,8 & 21,8 & 14,3 & 39,2 \\
\hline PV03-44 & 35,1 & 11,6 & 50,8 & 34,0 & 18,4 & 58,6 \\
\hline Média & 27,3 & 12,1 & 42,7 & 26,5 & 16,8 & 47,8 \\
\hline
\end{tabular}

(1) 1 o $\rightarrow 2$ o: porcentual de incremento do primeiro para o segundo ciclo; $2 \mathrm{o} \rightarrow 3 \mathrm{o}$ : porcentual de incremento do segundo para o terceiro ciclo; 1은 $\rightarrow$ 우 porcentual de incremento do primeiro para o terceiro ciclo. 
O número de folhas presentes na planta, na época da colheita do cacho, apresentou diferenças em todos os ciclos, possibilitando a formação de alguns grupos distintos (Tabela 4). No primeiro ciclo, 'Caipira', 'Nam', 'Pioneira', 'FHIA-18' e 'FHIA-01' formaram o grupo com maior número de folhas; 'SH3640', 'PV03-44' e 'Grande Naine', grupo intermediário; e 'Prata Anã' integrou o grupo com menor número de folhas. No segundo ciclo, houve a distinção em apenas dois grupos: um formado pelos genótipos Pioneira e Nam, com maior número de folhas, e o outro formado pelos demais, com menor número de folhas. Na variedade Prata Anã, Flores (2000), Silva et al. (2000), Donato (2003), Donato et al. (2003) e Lins (2005) encontraram valores superiores aos obtidos neste trabalho, em que ela aparece quase sempre com número de folhas na colheita inferior aos demais genótipos. No terceiro ciclo, houve novamente a formação de três grupos: 1, 'Nam', 'Pioneira', 'FHIA-18',
'PV03-44' e 'Prata Anã', com mais folhas; 2, 'Caipira' e 'FHIA-01'; e 3, 'SH3640' e 'Grande Naine', com menos folhas.

A média do número de folhas no primeiro ciclo foi inferior à média dos demais ciclos e também à média geral, característica também observada em outros trabalhos (Flores, 2000; Silva et al., 2000; Donato et al., 2003). Este resultado era esperado, já que no primeiro ciclo o pomar ainda não está bem formado, a cobertura morta, ou "mulching", constituída pelos restos culturais tais como partes do cacho, pseudocaule, folhas e perfilhos ainda é insuficiente para manter a umidade (Oliveira \& Souza, 2003) e promover a reciclagem de nutrientes, situações que ocorrem nos ciclos subseqüentes, dando subsídio à planta para manter maior número de folhas até a colheita. Caso oposto ocorreria se houvesse ataques severos de sigatoka-amarela, onde as cultivares suscetíveis apresentariam menor número de folhas no

Tabela 3. Duração média do ciclo completo e das fases de pré-floração e pós-floração de nove genótipos de bananeira em três ciclos na Zona da Mata Mineira ${ }^{(1)}$.

\begin{tabular}{|c|c|c|c|c|c|c|c|c|c|}
\hline \multirow[t]{2}{*}{ Genótipo } & \multicolumn{3}{|c|}{ Dias do plantio à colheita } & \multicolumn{3}{|c|}{ Dias do plantio ao florescimento } & \multicolumn{3}{|c|}{ Dias do florescimento à colheita } \\
\hline & $1^{\circ}$ ciclo & $2^{\circ}$ ciclo & $3^{\circ}$ ciclo & $1^{\circ}$ ciclo & $2^{\circ}$ ciclo & $3^{\circ}$ ciclo & $1^{\circ}$ ciclo & $2^{\circ}$ ciclo & $3^{\circ}$ ciclo \\
\hline Pioneira & $412,1 \mathrm{a}$ & $637,2 \mathrm{a}$ & $960,1 \mathrm{a}$ & $264,3 a$ & $499,4 a$ & $795,5 \mathrm{a}$ & $147,8 \mathrm{a}$ & $137,8 \mathrm{a}$ & $164,6 \mathrm{~b}$ \\
\hline FHIA-18 & $427,6 \mathrm{a}$ & $677,4 a$ & $1.012,5 \mathrm{a}$ & $292,3 a$ & $558,9 b$ & $887,5 b$ & $135,4 \mathrm{a}$ & $118,4 \mathrm{a}$ & $125,1 \mathrm{a}$ \\
\hline SH3640 & $461,6 \mathrm{a}$ & $850,1 \mathrm{c}$ & $1.183,3 \mathrm{c}$ & $323,1 b$ & $719,5 \mathrm{c}$ & $1.037,9 \mathrm{c}$ & $138,5 \mathrm{a}$ & $130,5 \mathrm{a}$ & $145,4 \mathrm{a}$ \\
\hline Prata Anã & $466,9 \mathrm{a}$ & $704,7 b$ & $1.040,9 \mathrm{~b}$ & $287,3 \mathrm{a}$ & $576,1 \mathrm{~b}$ & $901,8 b$ & $179,6 \mathrm{~b}$ & $128,7 \mathrm{a}$ & $139,1 \mathrm{a}$ \\
\hline PV03-44 & $470,1 \mathrm{a}$ & $721,1 b$ & $1.074,0 \mathrm{~b}$ & $280,2 a$ & $566,2 b$ & $910,7 b$ & $190,0 \mathrm{~b}$ & $154,9 \mathrm{~b}$ & $163,3 b$ \\
\hline FHIA-01 & $475,9 a$ & $838,3 \mathrm{c}$ & $1.137,2 \mathrm{c}$ & $331,9 b$ & $690,7 \mathrm{c}$ & $1.012 .1 \mathrm{c}$ & $143,9 a$ & $147,6 \mathrm{~b}$ & $125,0 \mathrm{a}$ \\
\hline Nam & $496,0 \mathrm{a}$ & $737,8 b$ & $1.053,0 \mathrm{~b}$ & $343,9 b$ & $600,0 \mathrm{~b}$ & $910,0 \mathrm{~b}$ & $152,1 \mathrm{a}$ & $137,9 \mathrm{a}$ & $142,9 a$ \\
\hline Grande Naine & $513,0 \mathrm{a}$ & $962,9 d$ & $1.206,9 \mathrm{c}$ & $370,9 b$ & $832,7 d$ & $1.067,1 \mathrm{c}$ & $142,2 \mathrm{a}$ & $130,2 a$ & $139,8 \mathrm{a}$ \\
\hline Caipira & $673,9 b$ & $910,7 \mathrm{~d}$ & $1.177,3 \mathrm{c}$ & $539,5 \mathrm{c}$ & $761,0 \mathrm{c}$ & $1.019,5 \mathrm{c}$ & $134,4 \mathrm{a}$ & $149,7 \mathrm{~b}$ & $157,8 \mathrm{~b}$ \\
\hline Média & $488,6 \mathrm{~A}$ & $782,2 \mathrm{~B}$ & $1.093,9 \mathrm{C}$ & $337,0 \mathrm{~A}$ & $645,0 \mathrm{~B}$ & $949,1 \mathrm{C}$ & $151,5 \mathrm{~B}$ & $137,3 \mathrm{~A}$ & $144,8 \mathrm{~B}$ \\
\hline
\end{tabular}

(1) Médias seguidas pela mesma letra, minúscula nas colunas e maiúscula nas linhas, pertencem ao mesmo grupo, pelo teste de Scott-Knott, a 5\% de probabilidade.

Tabela 4. Número de folhas vivas presentes no florescimento e na colheita de nove genótipos de bananeira em três ciclos na Zona da Mata Mineira ${ }^{(1)}$.

\begin{tabular}{|c|c|c|c|c|c|c|c|c|}
\hline \multirow[t]{2}{*}{ Genótipo } & \multicolumn{4}{|c|}{ Folhas vivas no florescimento } & \multicolumn{4}{|c|}{ Folhas vivas na colheita } \\
\hline & $1^{\circ}$ ciclo & $2^{\circ}$ ciclo & $3^{\circ}$ ciclo & Média & $1^{\circ}$ ciclo & $2^{0}$ ciclo & $3^{\circ}$ ciclo & Média \\
\hline Caipira & $11,4 \mathrm{a}$ & $11,5 \mathrm{a}$ & $11,8 \mathrm{a}$ & $11,6 \mathrm{a}$ & $6,0 \mathrm{a}$ & $4,9 b$ & $4,6 b$ & $5,2 \mathrm{a}$ \\
\hline Nam & $12,7 \mathrm{a}$ & $11,5 \mathrm{a}$ & $11,3 \mathrm{a}$ & $11,9 \mathrm{a}$ & $5,7 \mathrm{a}$ & $6,4 a$ & $6,2 \mathrm{a}$ & $6,1 \mathrm{a}$ \\
\hline Pioneira & $11,8 \mathrm{a}$ & $13,1 \mathrm{a}$ & $11,5 \mathrm{a}$ & $12,1 \mathrm{a}$ & $4,7 \mathrm{a}$ & $6,2 \mathrm{a}$ & $6,7 \mathrm{a}$ & $5,9 \mathrm{a}$ \\
\hline FHIA-18 & $11,7 \mathrm{a}$ & $10,6 \mathrm{a}$ & $10,2 \mathrm{a}$ & $10,8 \mathrm{a}$ & $4,5 \mathrm{a}$ & $5,0 \mathrm{~b}$ & $5,3 \mathrm{a}$ & $4,9 \mathrm{a}$ \\
\hline FHIA-01 & $13,1 \mathrm{a}$ & $10,9 a$ & $10,1 \mathrm{a}$ & $11,4 \mathrm{a}$ & $4,3 \mathrm{a}$ & $5,0 \mathrm{~b}$ & $4,9 \mathrm{~b}$ & $4,7 \mathrm{a}$ \\
\hline SH3640 & $12,3 \mathrm{a}$ & $9,8 \mathrm{a}$ & $10,3 \mathrm{a}$ & $10,8 \mathrm{a}$ & $3,5 b$ & $4,3 b$ & $3,0 \mathrm{c}$ & $3,6 b$ \\
\hline PV03-44 & $12,7 \mathrm{a}$ & $11,5 \mathrm{a}$ & $11,0 \mathrm{a}$ & $11,7 \mathrm{a}$ & $3,3 b$ & $4,7 b$ & $5,4 a$ & $4,5 b$ \\
\hline Grande Naine & $11,5 \mathrm{a}$ & $10,6 a$ & $10,9 a$ & $11,0 \mathrm{a}$ & $2,8 \mathrm{~b}$ & $4,3 b$ & $3,4 \mathrm{c}$ & $3,5 b$ \\
\hline Prata Anã & $14,7 \mathrm{a}$ & $12,9 a$ & $13,3 \mathrm{a}$ & $13,7 \mathrm{a}$ & $1,3 \mathrm{c}$ & $3,5 \mathrm{~b}$ & $7,2 \mathrm{a}$ & $4,0 \mathrm{~b}$ \\
\hline Média & $12,4 \mathrm{~A}$ & $11,4 \mathrm{~B}$ & $11,2 \mathrm{~B}$ & 11,7 & $4,0 \mathrm{~B}$ & $4,9 \mathrm{~A}$ & $5,2 \mathrm{~A}$ & 4,7 \\
\hline
\end{tabular}

${ }^{(1)}$ Médias seguidas pela mesma letra, minúscula nas colunas e maiúscula nas linhas, pertencem ao mesmo grupo, pelo teste de Scott-Knott, a 5\% de probabilidade. 
segundo e terceiro ciclos, enquanto as resistentes apresentariam comportamento semelhante ao ocorrido.

Apesar de, no florescimento, 'Prata Anã' ter apresentado o maior número de folhas entre os genótipos estudados nos três ciclos, esta variedade sofreu uma drástica redução $(91,4 \%)$ ao longo do seu primeiro ciclo produtivo (Tabela 5), o que pode ter ocorrido graças à sua suscetibilidade à sigatoka-amarela (Alves, 1997; Matos et al., 2001), já que, entre os genótipos avaliados, recebeu a maior nota quanto a esta característica, neste ciclo. Por sua vez, e ainda neste ciclo, 'Caipira' conseguiu reter o maior número de folhas, apresentando o menor porcentual de perda (47,3\%). Pode-se associar também este resultado à sua resistência à sigatoka-amarela (Tabela 6).

No segundo ciclo, apesar de haver redução no seu porcentual de perda de folhas, 'Prata Anã' mostrou grande fragilidade, apresentado $72,7 \%$, o maior valor encontrado neste ciclo. Desta vez a variedade Nam apresentou menor porcentual de perda de folhas, evidenciando, também, sua resistência à sigatoka-amarela.
Quanto ao terceiro ciclo, a variedade Caipira ficou entre as de maior porcentual de perda $(60,7 \%)$, pouco inferior ao da Grande Naine com $69 \%$. Pioneira foi o híbrido que proporcionalmente menos folhas perdeu neste ciclo, com apenas $41,8 \%$. Ao se analisar a média dos três ciclos, tem-se 'Nam' como o genótipo com o maior grau de persistência de suas folhas, e porcentual médio de perda de 48,4\%. Por outro lado, 'Prata Anã' foi o genótipo com a maior perda de folhas no período entre o florescimento e a colheita do cacho.

Os genótipos Caipira, Nam e PV03-44 se destacam dos demais quanto à ausência de sigatoka-amarela no florescimento nos três ciclos avaliados, assim como na média, recebendo nota 0 em quase todas as plantas (Tabela 6). Este resultado confirma a resistência das variedades Caipira, Nam (Silva et al., 2003a) e PV03-44 (Siviero \& Ledo, 2002). 'Pioneira', apesar de na média dos três ciclos não estar agrupado com os genótipos que mostraram resistência à doença, apresentou poucos sintomas de sigatoka-amarela no segundo e terceiro ciclos, ficando, apenas no primeiro ciclo,

Tabela 5. Porcentual de morte foliar observado entre o florescimento e a colheita do cacho de nove genótipos de bananeira em três ciclos na Zona da Mata Mineira.

\begin{tabular}{|c|c|c|c|c|}
\hline \multirow[t]{2}{*}{ Genótipo } & \multicolumn{3}{|c|}{ Porcentual de perda de folhas durante o ciclo } & \multirow[t]{2}{*}{ Média } \\
\hline & $1^{\circ}$ ciclo & $2^{\circ}$ ciclo & $3^{\circ}$ ciclo & \\
\hline Caipira & 47,3 & 57,5 & 60,7 & 55,2 \\
\hline Nam & 55,4 & 44,6 & 45,1 & 48,4 \\
\hline Pioneira & 59,8 & 52,5 & 41,8 & 51,3 \\
\hline FHIA-8 & 61,8 & 53,0 & 48,1 & 54,3 \\
\hline FHIA-1 & 67,4 & 54,2 & 51,8 & 57,8 \\
\hline SH3640 & 71,8 & 56,6 & 71,0 & 66,5 \\
\hline PV03-44 & 74,3 & 59,0 & 50,7 & 61,3 \\
\hline Grande Naine & 76,1 & 59,6 & 69,0 & 68,2 \\
\hline Prata Anã & 91,4 & 72,7 & 45,8 & 70,0 \\
\hline Média & 67,2 & 56,6 & 53,8 & 59,2 \\
\hline
\end{tabular}

Tabela 6. Notas atribuídas à incidência de sigatoka-amarela no florescimento e na colheita de nove genótipos de bananeira em três ciclos na Zona da Mata Mineira ${ }^{(1)}$.

\begin{tabular}{|c|c|c|c|c|c|c|c|c|}
\hline \multirow[t]{2}{*}{ Genótipo } & \multicolumn{4}{|c|}{ Sigatoka-amarela no florescimento } & \multicolumn{4}{|c|}{ Sigatoka-amarela na colheita } \\
\hline & $1^{0}$ ciclo & $2^{\circ}$ ciclo & $3^{\circ}$ ciclo & Média & $1^{0}$ ciclo & $2^{\underline{0} \text { ciclo }}$ & $3^{\circ}$ ciclo & Média \\
\hline Caipira & $0,0 \mathrm{a}$ & $0,0 \mathrm{a}$ & $0,0 \mathrm{a}$ & $0,0 \mathrm{a}$ & $0,8 \mathrm{a}$ & $0,4 a$ & $0,7 \mathrm{a}$ & $0,6 \mathrm{a}$ \\
\hline Nam & $0,0 \mathrm{a}$ & $0,0 \mathrm{a}$ & $0,0 \mathrm{a}$ & $0,0 \mathrm{a}$ & $1,2 \mathrm{a}$ & $0,7 \mathrm{a}$ & $0,4 a$ & $0,7 \mathrm{a}$ \\
\hline PV03-44 & $0,4 \mathrm{a}$ & $0,0 \mathrm{a}$ & $0,0 \mathrm{a}$ & $0,1 \mathrm{a}$ & $1,7 \mathrm{~b}$ & $1,0 \mathrm{a}$ & $0,5 \mathrm{a}$ & $1,0 \mathrm{a}$ \\
\hline FHIA-01 & $1,3 b$ & $1,5 b$ & $0,8 \mathrm{~b}$ & $1,2 \mathrm{c}$ & $1,6 b$ & $1,5 b$ & $1,6 b$ & $1,6 \mathrm{~b}$ \\
\hline Grande Naine & $1,5 b$ & $1,0 \mathrm{~b}$ & $0,7 \mathrm{~b}$ & $1,1 \mathrm{c}$ & $0,9 \mathrm{a}$ & $2,0 \mathrm{c}$ & $1,6 b$ & $1,5 b$ \\
\hline Pioneira & $1,6 b$ & $0,1 \mathrm{a}$ & $0,0 \mathrm{a}$ & $0,6 b$ & $1,3 a$ & $0,6 \mathrm{a}$ & $0,7 \mathrm{a}$ & $0,9 \mathrm{a}$ \\
\hline SH3640 & $2,3 \mathrm{c}$ & $2,1 \mathrm{c}$ & $1,7 \mathrm{c}$ & $2,0 \mathrm{e}$ & $2,0 \mathrm{~b}$ & $3,1 d$ & $1,6 b$ & $2,2 \mathrm{c}$ \\
\hline FHIA-18 & $2,4 \mathrm{c}$ & $1,5 b$ & $0,6 \mathrm{~b}$ & $1,5 \mathrm{~d}$ & $2,0 \mathrm{~b}$ & $1,3 b$ & $1,3 b$ & $1,5 b$ \\
\hline Prata Anã & $2,5 \mathrm{c}$ & $2,0 \mathrm{c}$ & $0,4 \mathrm{a}$ & $1,6 \mathrm{~d}$ & $2,5 \mathrm{~b}$ & $2,9 \mathrm{~d}$ & $3,5 \mathrm{c}$ & $3,0 \mathrm{~d}$ \\
\hline Média & $1,3 \mathrm{C}$ & $0,9 \mathrm{~B}$ & $0,5 \mathrm{~A}$ & 0,9 & $1,6 \mathrm{~A}$ & $1,5 \mathrm{~A}$ & $1,3 \mathrm{~A}$ & 1,5 \\
\hline
\end{tabular}

${ }^{(1)}$ Médias seguidas pela mesma letra, minúscula nas colunas e maiúscula nas linhas, pertencem ao mesmo grupo, pelo teste de Scott-Knott, a 5\% de probabilidade. 
fora do grupo que apresentou superioridade nesta característica. Siviero \& Ledo (2002) também encontraram resistência deste genótipo à sigatoka-amarela.

No que se refere à incidência de sigatoka-amarela no florescimento, pôde-se observar redução do primeiro para o terceiro ciclo, nos genótipos Pioneira, FHIA-18 e Prata Anã. Na análise da média de todos os genótipos em cada ciclo, também é possível verificar a diminuição gradual dos danos causados pela sigatoka-amarela. Esse comportamento advém do fato de que o bananal só se estabelece a partir do segundo ou terceiro ciclo, melhorando as condições edáficas e, conseqüentemente, o vigor e a capacidade de tolerar doenças (Alves \& Lima, 2000). Uma outra explicação é dada por Cordeiro \& Matos (2000), ao sugerirem que plantas mantidas sob condições sombreadas apresentam pouca ou nenhuma doença. Este sombreamento só ocorre a partir do segundo ciclo, já que os perfilhos nascem e crescem sob as copas das plantas-mãe

As notas de incidência de sigatoka-amarela atribuídas aos genótipos, na época da colheita, foram maiores que as atribuídas na época do florescimento. Durante o agrupamento promovido pelo teste de médias de Scott-Knott no primeiro ciclo, apenas dois grupos foram formados. 'Caipira', 'Grande Naine', 'Nam' e 'Pioneira' receberam notas variando de 0,8 a 1,3. No outro grupo, formado por 'FHIA-01', 'PV03-44', 'SH3640', 'FHIA-18' e 'Prata Anã', as notas variaram de 1,6 a 2,5. No segundo ciclo, houve formação de quatro agrupamentos de médias: 1, 'Caipira', 'Nam', 'PV03-44' e 'Pioneira', grupo que recebeu as menores notas (0,4 a 1,0); 2, 'FHIA-18' e 'FHIA-01', com 1,3 e 1,5, respectivamente; 3, 'Grande Naine' (2,0); e 4, 'SH3640' com 3,1, maior nota para este ciclo. O terceiro ciclo não apresentou muitas mudanças em relação ao primeiro e ao segundo ciclos.
Não houve diferença significativa entre os ciclos avaliados, evidenciando que o ciclo não influenciou significativamente na incidência de sigatoka-amarela na colheita (Tabela 6). Quanto à média dos genótipos durante os três ciclos, quatro grupos foram formados, recebendo destaque 'Caipira', 'Nam', 'Pioneira' e 'PV03-44' como os que apresentaram menor incidência de sigatoka-amarela na colheita, e 'Prata Anã' como o genótipo mais suscetível à doença.

A quantidade de perfilhos emitida até o décimo mês após o plantio não apresentou diferença significativa entre os nove genótipos (Tabela 7). Na segunda contagem, que ocorreu do $10^{\circ}$ ao $11^{\circ}$ mês após o plantio, houve a formação de três grupos distintos, destacando-se 'Nam' e 'Pioneira' com o maior número de perfilhos, seguidos por 'PV03-44', 'Prata Anã', 'Caipira' e 'Grande Naine' com 4,5 a 3,8 perfilhos, e 'FHIA-18', 'FHIA-01' e 'SH3640', apresentando de 2,7 a 1,8. Na terceira contagem, apenas dois grupos foram formados, mais uma vez com a presença dos genótipos Nam e Pioneira, no grupo com maior número de perfilhos, desta vez participando também a 'Caipira'; o outro grupo foi formado pelos demais. Na quarta e quinta contagens, a quantidade de grupos distintos (dois) se repetiu, porém houve variações nos genótipos que emitiram maior número de perfilhos. Finalmente, na última contagem do número de perfilhos presentes na época do desbaste, pôde-se observar a formação de três grupos distintos.

No somatório de todos os perfilhos emitidos durante a avaliação dessa característica, pôde-se destacar 'Nam' como o genótipo que apresentou a maior quantidade, e 'FHIA-18', 'FHIA-01' e 'SH3640' as menores quantidades de perfilhos.

Tabela 7. Quantidade e época de emissão de perfilhos de nove genótipos de bananeira na Zona da Mata Mineira. ${ }^{(1)}$

\begin{tabular}{|c|c|c|c|c|c|c|c|}
\hline Genótipo & $\begin{array}{l}\text { Total nos } \\
\text { três ciclos }\end{array}$ & $\begin{array}{c}\text { Até o } \\
10^{\circ} \text { mês }\end{array}$ & $\begin{array}{c}\text { Do } 10^{\circ} \text { ao } \\
15^{\circ} \text { mês }\end{array}$ & $\begin{array}{c}\text { Do } 15^{\circ} \text { ao } \\
18^{\circ} \text { mês }\end{array}$ & $\begin{array}{c}\text { Do } 18^{\circ} \text { ao } \\
23^{\circ} \text { mês }\end{array}$ & $\begin{array}{c}\text { Do } 23^{\circ} \text { ao } \\
30^{\circ} \text { mês }\end{array}$ & $\begin{array}{c}\text { Do } 30^{\circ} \text { ao } \\
34^{\circ} \text { mês }\end{array}$ \\
\hline$\overline{\text { Nam }}$ & $42,8 \mathrm{a}$ & $8,8 \mathrm{a}$ & $6,9 a$ & $7,0 \mathrm{a}$ & $7,0 \mathrm{a}$ & $7,7 a$ & $5,4 a$ \\
\hline Caipira & $33,0 \mathrm{~b}$ & $6,2 \mathrm{a}$ & $3,8 b$ & $5,6 a$ & $5,3 a$ & $7,2 \mathrm{a}$ & $5,0 \mathrm{a}$ \\
\hline Pioneira & $28,8 b$ & $6,0 \mathrm{a}$ & $5,5 \mathrm{a}$ & $6,2 \mathrm{a}$ & $3,3 b$ & $4,4 \mathrm{~b}$ & $3,4 \mathrm{~b}$ \\
\hline PV03-44 & $27,1 \mathrm{~b}$ & $6,0 \mathrm{a}$ & $4,5 b$ & $4,3 b$ & $5,2 \mathrm{a}$ & $3,7 \mathrm{~b}$ & $3,4 \mathrm{~b}$ \\
\hline Grande Naine & $25,4 b$ & $6,8 \mathrm{a}$ & $3,8 \mathrm{~b}$ & $4,0 \mathrm{~b}$ & $5,5 \mathrm{a}$ & $2,8 \mathrm{~b}$ & $2,6 \mathrm{c}$ \\
\hline Prata Anã & $23,8 b$ & $5,5 a$ & $4,0 \mathrm{~b}$ & $4,7 b$ & $3,2 b$ & $3,1 \mathrm{~b}$ & $3,3 b$ \\
\hline FHIA-18 & $16,6 \mathrm{c}$ & $5,3 a$ & $2,7 \mathrm{c}$ & $3,6 \mathrm{~b}$ & $1,8 \mathrm{~b}$ & $2,2 b$ & $1,0 \mathrm{c}$ \\
\hline FHIA01 & $15,4 \mathrm{c}$ & $4,6 a$ & $2,3 \mathrm{c}$ & $3,1 \mathrm{~b}$ & $1,9 \mathrm{~b}$ & $2,3 b$ & $1,3 \mathrm{c}$ \\
\hline SH3640 & $10,6 \mathrm{c}$ & $3,3 a$ & $1,8 \mathrm{c}$ & $2,4 \mathrm{~b}$ & $0,8 \mathrm{~b}$ & $1,2 \mathrm{~b}$ & $1,1 \mathrm{c}$ \\
\hline
\end{tabular}

${ }^{(1)}$ Médias seguidas pela mesma letra, na coluna, pertencem ao mesmo grupo, pelo teste de Scott-Knott, a 5\% de probabilidade. 


\section{Conclusões}

1. O genótipo Grande Naine apresenta o menor porte, e Prata Anã, FHIA-01 e SH3640 apresentam o maior diâmetro.

2. 'Pioneira' e 'FHIA-18' apresentam maior precocidade.

3. 'Nam' e 'Caipira' apresentam maior perfilhamento.

4. Os genótipos FHIA-01, FHIA-18 e SH3640 são identificados como superiores.

\section{Referências}

ALVES, E.J. (Org.). A cultura da banana: aspectos técnicos, socioeconômicos e agroindustriais. Brasília: Embrapa-SPI/Cruz das Almas: Embrapa-CNPMF, 1997. 585p.

ALVES, E.J.; LIMA, M.B. Estabelecimento do bananal. In: CORDEIRO, Z.J.M. (Org.). Banana: produção: aspectos técnicos. Brasília: Embrapa Comunicação para Transferência de Tecnologia, 2000. p.73-82. (Frutas do Brasil, 1).

AMBIENTE BRASIL. Classificação dos climas do Brasil. Disponível em: <http://www.ambientebrasil.com.br/ composer.php3 ?base $=. /$ natural/index.html\&conteudo $=. /$ natural $/$ clima.html>. Acesso em: 29 jan. 2006.

BANZATTO, D.A.; KRONKA, S.N. Experimentação agrícola. Jaboticabal: Funep, 1989. 247p.

BRASIL. Ministério da Agricultura, Pecuária e Abastecimento. Evolução do mercado mundial de frutas. Disponível em: $<$ http://www.agricultura.gov.br/pls/portal/docs/PAGE/MAPA/ MENU_LATERAL/AGRICULTURA_PECUARIA/ ESTUDOS_PUBLICACOES/ESTUDO_MERCADO_FRUTAS/ CAPITULO_3.PDF>. Acesso em: 25 fev. 2006.

CLASSIFICAÇÃO do clima de Köppen. In: WIKIPÉDIA: a enciclopédia livre. Disponível em: <http://pt.wikipedia.org/wiki/ Classifica\%C3\%A7\%C3\%A3o_do_clima_de_K\%C3\%B6ppen>. Acesso em: 29 jan. 2006.

COMISSÃO DE FERTILIDADE DO SOLO DO ESTADO DE MINAS GERAIS (Lavras, MG). Recomendações para o uso de corretivos e fertilizantes em Minas Gerais: 4aa aproximação. Lavras, 1989. 159p.

CORDEIRO, Z.J.M.; MATOS, A.P. de. Doenças fúngicas e bacterianas. In: CORDEIRO, Z.J.M. (Org.). Banana: fitossanidade. Brasília: Embrapa Comunicação para Transferência de Tecnologia, 2000. p.36-64.

DONATO, S.L.R. Comportamento de variedades e híbridos de bananeira (Musa spp.), em primeiro ciclo de produção no sudoeste da Bahia, região de Guanambi. 2003. 115p. Dissertação (Mestrado) - Universidade Federal de Pelotas, Pelotas.

DONATO, S.L.R.; SILVA, S. de O. e; PASSOS, A.R.; LIMA NETO, F.P.; LIMA, M.B. Avaliação de variedades e híbridos de bananeiras sob irrigação. Revista Brasileira de Fruticultura, v.25, p.348-351, 2003 .
EMBRAPA. Centro Nacional de Pesquisa de Solos (Rio de Janeiro, RJ). Sistema brasileiro de classificação de solos. Brasília: Embrapa-SPI; Rio de Janeiro: Embrapa-CNPS, 1999. 412p.

FAO. Food and Agriculture Organization of the United Nations. Faostat. Disponível em: <http://faostat.fao.org/>. Acesso em: 28 jan. 2006.

FERREIRA, D.F. Manual do sistema Sisvar para análises estatísticas. Lavras: Ufla, 2000. 63p.

FLORES, J.C. de O. Avaliação de cultivares e híbridos de bananeira (Musa spp.) em quatro ciclos de produção em Cruz das Almas, BA. 2000. 110p. Dissertação (Mestrado) - Universidade Federal da Bahia, Cruz das Almas.

GAIVA, H.N. Avaliação de algumas características do desenvolvimento e da produção de três cultivares de bananeira (Musa spp.), na baixada cuiabana - MT. 1992. 103p. Tese (Doutorado) - Universidade Estadual Paulista, Jaboticabal.

IBGE. Mesorregiões, microrregiões e municípios. Disponível em: <http://www.ibge.gov.br>. Acesso em: 18 jan. 2006.

LEDO, A. da S.; LÉDO, F.J. da; SILVA, S. de O. Avaliação de cultivares de banana em Rio Branco, Acre. Rio Branco: EmbrapaCPAF-AC, 1997. 16p. (Boletim de pesquisa, 15). Disponível em: $<$ http://www.cpafac.embrapa.br/pdf/bp15.pdf $>$. Acesso em: $23 \mathrm{de}$ jan. 2006.

LEITE, J.B.V.; SILVA, S. de O. e; ALVES, E.J.; LINS, R.D.; JESUS, O.N. de. Caracteres da planta e do cacho de genótipos de bananeira, em quatro ciclos de produção, em Belmonte, Bahia. Revista Brasileira de Fruticultura, v.25, p.443-447, 2003.

LEONEL, S.; GOMES, E.M.; PEDROSO, C.J. Desempenho agronômico de bananeiras micropropagadas em Botucatu, SP. Revista Brasileira de Fruticultura, v.26, p.245-248, 2004.

LIMA, M.B.; SILVA, S. de O. e; JESUS, O.N. de; OLIVEIRA, W.S.J. de; GARRIDO, M. da S.; AZEVEDO, R.L. de. Avaliação de cultivares e híbridos de bananeira no Recôncavo Baiano. Ciência e Agrotecnologia, v.29, p.515-520, 2005.

LINS, R.D. Avaliação de genótipos de bananeira em dois ciclos de produção no município de Una, Bahia. 2005. 46p. Dissertação (Mestrado) - Universidade Federal da Bahia, Cruz das Almas.

MATOS, A.P. de; BORGES, M. de F.; CORDEIRO, Z.J.M.; SILVA, S. de O. e. Reação de genótipos de bananeira à infecção natural pela Sigatoka-amarela. Magistra, v.13, 2001. Disponível em: <http:// www.magistra.ufba.br/publica/magist13_2/01-13_2-02c.html>. Acesso em: 23 nov. 2006.

OLIVEIRA, C.A.P. de; SOUZA, C.M. de. Influência da cobertura morta na umidade, incidência de plantas daninhas e de broca-dorizoma (Cosmopolites sordidus) em um pomar de bananeiras (Musa spp.). Revista Brasileira de Fruticultura, v.25, p.345-347, 2003.

PEREIRA, L.V.; SILVA, S. de O. e; ALVES, E.J.; SILVA, C.R. de R. e. Avaliação de cultivares e híbridos de bananeira em Lavras, MG. Ciência e Agrotecnologia, v.27, p.17-25, 2003.

PEREIRA, M.C.T.; SALOMÃO, L.C.C.; SILVA, S. de O. e; SEDIYAMA, C.S.; COUTO, F.A.D'A.; SILVA NETO, S.P. da. Crescimento e produção de primeiro ciclo da bananeira 'Prata Anã' 
(AAB) em sete espaçamentos. Pesquisa Agropecuária Brasileira, v.35, p.1377-1387, 2000.

SILVA, S. de O. e; FLORES, J.C. de O.; LIMA NETO, F.P. Avaliação de cultivares e híbridos de bananeira em quatro ciclos de produção. Pesquisa Agropecuária Brasileira, v.37, p.1567-1574, 2002.

SILVA, S. de O. e; GASPAROTTO, L.; MATOS, A.P. de; CORDEIRO, Z.J.M.; FERREIRA, C.F.; RAMOS, M.M.; JESUS, O.N. de. Programa de melhoramento de bananeira no Brasil: resultados recentes. Cruz das Almas: Embrapa Mandioca e Fruticultura, 2003a. 36p. (Documentos, 123).

SILVA, S. de O. e; PASSOS, A.R.; DONATO, S.L.R.; SALOMÃO, L.C.C.; PEREIRA, L.V.; RODRIGUES, M.G.V.; LIMANETO, F.P.; LIMA, M.B. Avaliação de genótipos de bananeira em diferentes ambientes. Ciência e Agrotecnologia, v.27, p.737-748, 2003b.

SILVA, S. de O. e; ROCHA, S.A.; ALVES, E.J.; DI CREDICO, M.; PASSOS, A.R. Caracterização morfológica e avaliação de cultivares e híbridos de bananeira. Revista Brasileira de Fruticultura, v.22, p.161-169, 2000.
SILVA, S. de O. e; SHEPHERD, K.; DANTAS, J.L.L.; ALVES, E.J.; BORGES, A.L.; FANCELLI, M.; OLIVEIRA, S.L. de; OLIVEIRA, M. de A. Avanços do programa de pesquisa em Musa no CNPMF, Embrapa, Brasil. Cruz das Almas: Embrapa-CNPMF, 1996. 37p. (Documentos, 65).

SILVA, S. de O. e; SOUZA JÚNIOR, M.T.S.; ALVES, E.J.; SILVEIRA, J.R.S.; LIMA, M.B. Banana breeding program at Embrapa. Crop Breeding and Applied Biotechnology, v.1, p.399436, 2001.

SIVIERO, A.; LEDO, A. da S. Avaliação de genótipos de banana à Sigatoca-amarela na Amazônia Ocidental. Revista Brasileira de Fruticultura, v.24, p.724-726, 2002.

ZONETTI, P. da C.; SANTOS, P.C. dos; BOLIANI, A.C.; SCARPARE FILHO, J.A.; FIGUEIRA, A.V.; SOUZA, S.A.C.D. de; TULMANN NETO, A. Avaliação de variante somaclonal de porte baixo de bananeira 'Nanicão Jangada' (Musa sp.) em duas densidades. Revista Brasileira de Fruticultura, v.25, p.471-474, 2003.

Recebido em 26 de abril de 2006 e aprovado em 20 de novembro de 2006 